\title{
KARAKTERISTIK PEMANFAATAN PENGGUNAAN BAN DALAM KENDARAAN BEKAS RODA EMPAT TERHADAP CAMPURAN LASTON
}

\author{
Ilham Saputra Prayogi ${ }^{1}$, Salonten ${ }^{2}$ dan Ina Elvina ${ }^{3}$ \\ ${ }^{123}$ Program Studi Teknik Sipil, Fakultas Teknik, Universitas Palangka Raya \\ E-mail: ilhamogii78@gmail.com¹, salonten@jts.upr.ac.id²,dan \\ inaelvina@eng.upr.ac.id ${ }^{3} /$ HP.+6281251792567 ${ }^{1}$
}

\begin{abstract}
ABSTRAK
Laston adalah salah satu tipe perkerasan aspal yang paling sering digunakan di Indonesia. Terdiri atas 3 lapis, yaitu $A C$-WC (Asphalt Concrete-Wearing Course), $A C$-BC (Asphalt Concrete - Binder Course), dan AC-BASE (Asphalt Concrete-Base) sebagai pondasi. Penelitian ini dilakukan untuk mengetahui sejauh mana manfaat penggunaan ban dalam bekas kendaraan roda empat sebagai bahan tambahan pada campuran $A C-B C$ (Asphalt Concrete - Binder Course) yang diharapkan penggunaannya dapat meningkatkan mutu perkerasan lentur jalan raya dan sekaligus salah satu langkah penanganan pengurangan sisa penggunaan limbah ban dalam bekas yang tidak terpakai. Untuk mengetahui pengaruh ban dalam bekas, dibuat komposisi campuran dengan 5 (lima) variasi kadar aspal. Berdasarkan Tes Marshall dengan komposisi tersebut diperoleh nilai Kadar Aspal Optimum (KAO) sebesar $7,7 \%$, stabilitas $1450 \mathrm{~kg}$, nilai rongga dalam agregat (VMA) 22,30\%, rongga dalam campuran (VIM) 4,50\%, rongga terisi aspal (VFB) 80\%, hasil bagi Marshall (MQ) $450,60 \mathrm{~kg} / \mathrm{mm}$.
\end{abstract}

Kata Kunci: Laston AC-BC, Marshall, Ban Dalam Bekas Kendaraan Roda Empat

\section{ABSTRACT}

Laston is one of the most commonly used asphalt pavement types in Indonesia. Consists of 3 layers, namely $A C$-WC (Asphalt Concrete-Wearing Course), $A C-B C$ (Asphalt Concrete - Binder Course), and AC-BASE (Asphalt Concrete-Base) as the foundation. This research was conducted to determine the extent of the benefits of using tires in used four-wheeled vehicles as an additional ingredient in the $A C$ - $B C$ (Asphalt Concrete - Binder Course) mixture which is expected to be used to improve the quality of flexible road pavements and at the same time one of the steps to reduce waste use unused old tires. To determine the effect of used tires, a mixture composition with 5 (five) variations of asphalt content was made. Based on the Marshall test with this composition, the Optimum Asphalt Content (KAO) value is $7.7 \%$, the stability is $1450 \mathrm{~kg}$, the void in the aggregate (VMA) is $22.30 \%$, the cavity in the mixture (VIM) is $4.50 \%$, the cavity is filled with asphalt. (VFB) $80 \%$, Marshall quotient (MQ) $450.60 \mathrm{~kg} / \mathrm{mm}$.

Keywords: Laston AC-BC, Marshall, Used Four-Wheel Vehicle Tires 


\section{PENDAHULUAN}

\section{Latar Belakang}

Kasus kerusakan jalan yang terjadi di Indonesia pada umumnya berupa retak-retak (cracks), gelombang (corrugation), naiknya aspal ke permukaan jalan (bleeding) dan berupa lubanglubang (potholes) yang disebabkan oleh beberapa faktor diantaranya pengaruh mutu pelaksanaan, cuaca dan air yang dapat mempercepat turunnya kemampuan suatu perkerasan jalan. Air merupakan musuh utama perkerasan lentur karena dapat melemahakan ikatan antara agregat dan aspal, sehingga perlu mencari bahan material untuk meningkatkan kualitas aspal dan perkerasan lentur. Salah satu usaha mengurangi kerusakan dengan cara meningkatkan kualitas aspal dan perkerasan lentur yang dapat dilakukan dengan menambahkan bahan parutan karet ban dalam bekas kendaraan roda empat untuk mengurangi penggunaan aspal dan menggantikan batu sebagai agregat halus ke dalam campuran panas aspal beton. Road Research Centre, Ministry of Public Work di Kuwait menyatakan penambahan 2\% dan 5\% parutan ban bekas terhadap aspal dapat mencegah terjadinya retak-retak, bleeding dan memperkecil terjadinya pelepasan butir pada permukaan perkerasan lentur. Berdasarkan permasalahan di atas, maka dilakukan penelitian dengan memodifikasi Journal of The Civil Engineering Student, Vol. 1, No. 1, April 20192 campuran Asphalt Concrete - Binder Course $(A C-B C)$ dengan menggunakan parutan karet ban dalam bekas sebagai filler dengan metode pencampuran cara kering. Penelitian ini bertujuan untuk mengetahui pengaruh penggunaan parutan karet ban dalam bekas dengan sebagai filler pada campuran Asphalt Concrete - Binder Course $(A C-B C)$ dengan metode pencampuran cara kering terhadap parameter Marshall. Berdasarkan hipotesa diatas, maka perlu dilakukan penelitian terhadap pengaruh penggunaan parutan karet bekas sebagai bahan substitusi agregat terhadap karakteristik campuran Asphalt Concrete - Binder Course (AC - BC) sebesar 2\%, 4\%, $6 \%, 8 \%$, dan $10 \%$.

\section{Tujuan Penelitian}

Mengetahui Pengaruh pemanfaatan limbah sebagai bahan tambah Pengaruh pemanfaatan limbah parutan karet ban dalam bekas sebagai bahan tambah terhadap aspal campuran Asphalt Concrete - Binder Course $(A C-B C)$.

\section{METODE PENELITIAN}

\section{1) Umum}

Metode penelitian yang digunakan adalah metode uji laboratorium. Material yang akan digunakan dalam penelitian ini diperiksa terlebih dahulu di laboratorium untuk memperoleh karateristik dari material tersebut.

Data yang digunakan dilaboratorium digunakan untuk perencanaan campuran, selanjutnya dibuat benda uji (briket) sehingga diketahui karakteristik campuran.

\section{2) Lokasi dan Teknik Pengambilan Material}

Agregat diambil dari Quarry hampangan PT. Karya Sukses Sahabat, Desa 
Hampangen, Kecamatan Katingan Hilir, Kabupaten Katingan. Dengan waktu tempuh \pm 1,5 jam dari Palangka Raya. Sampel diambil secara acak dengan jumlah secukupnya pada lokasi pengambilan material tersebut.

\section{3) Metode Pengambilan Data}

Pengambilan data dilakukan dengan membuat briket/benda uji sebanyak 15 buah briket/benda uji untuk mencari (KAO) pada komposisi $100 \%$ ban dalam bekas, dengan 5 variasi kadar aspal, 6\%,6.5\%,7\%,7.5\%,8\% (3 briket/benda uji tiap kadar aspal). Metode pembuatan benda uji briket atau analisis pengujian Marshall mengacu pada prosedur Spesifikasi Bina Marga.

\section{HASIL \& PEMBAHASAN}

Hasil pemeriksaan gradasi dapat dilihat pada tabel berikut ini.

Tabel 1. Hasil Pemeriksaan Gradasi (Analisa Saringan)

\begin{tabular}{|c|c|c|c|c|c|c|c|c|c|}
\hline \multicolumn{2}{|c|}{ No. Saringan } & \multicolumn{2}{|c|}{ Agregat Kasar } & \multicolumn{2}{c|}{ Abu Batu } & \multicolumn{2}{c|}{ Pasir } & $\begin{array}{c}\text { Total } \\
\text { Kombinasi }\end{array}$ & Spesifikasi \\
\hline inch & $\mathrm{mm}$ & $100 \%$ & $36 \%$ & $100 \%$ & $36 \%$ & $100 \%$ & $28 \%$ & \\
\hline$\# 1$ & 25.4 & 100.00 & 36.00 & 100.00 & 36.00 & 100.00 & 28.00 & 100.00 & 100 \\
\hline$\# 3 / 4$ & 19.05 & 86.90 & 31.28 & 100.00 & 36.00 & 100.00 & 28.00 & 95.28 & $90-100$ \\
\hline$\# 1 / 2$ & 12.7 & 41.25 & 14.85 & 100.00 & 36.00 & 100.00 & 28.00 & 78.85 & $75-90$ \\
\hline$\# 3 / 8$ & 9.53 & 17.77 & 6.40 & 100.00 & 36.00 & 100.00 & 28.00 & 70.40 & $66-82$ \\
\hline No.4 & 4.75 & 6.38 & 2.30 & 81.45 & 29.32 & 100.00 & 28.00 & 59.62 & $46-64$ \\
\hline No.8 & 2.35 & 3.71 & 1.34 & 51.76 & 18.63 & 91.65 & 25.66 & 45.63 & $30-49$ \\
\hline No.16 & 1.18 & 2.07 & 0.75 & 35.06 & 12.62 & 66.78 & 18.70 & 32.07 & $18-38$ \\
\hline No.30 & 0.6 & 1.04 & 0.37 & 20.60 & 7.42 & 47.51 & 13.30 & 21.09 & $12-28$ \\
\hline No.50 & 0.3 & 0.46 & 0.17 & 10.48 & 3.77 & 27.00 & 7.56 & 11.50 & $7-20$ \\
\hline No.100 & 0.15 & 0.16 & 0.06 & 3.39 & 1.22 & 14.50 & 4.06 & 5.34 & $5-13$ \\
\hline No.200 & 0.075 & 0.04 & 0.02 & 0.31 & 0.11 & 12.50 & 3.50 & 3.63 & $4-8$ \\
\hline Pan & 0 & 0.00 & 0.00 & 0.00 & 0.00 & 0.00 & 0.00 & 0.00 & 0 \\
\hline
\end{tabular}

Pemeriksaan sifat-sifat fisik agregat yang lain yaitu pemeriksaan berat jenis, penyerapan, sand equivalent dapat dilihat pada tabel berikut.

Tabel 2. Hasil Pemeriksaan Sifat-sifat Fisik Agregat

\begin{tabular}{|c|c|c|c|c|c|}
\hline \multirow{2}{*}{ No } & \multirow{2}{*}{\multicolumn{2}{|c|}{ Uraian }} & \multicolumn{3}{|c|}{ Nomor Contoh } \\
\hline & & & I & II & II \\
\hline 1 & \multicolumn{2}{|c|}{ Tera tinggi penunjuk beban ke dalam gelas ukur (gelas dalm keadaan kosong) } & 10.00 & 10.00 & 10.00 \\
\hline 2 & \multicolumn{2}{|c|}{ Pembacaan skala lumpur dilihat pada dinding gelas ukur } & 5.40 & 5.50 & 5.30 \\
\hline 3 & \multicolumn{2}{|c|}{ Masukan beban, kemudian baca skala pada tangkai penunjuk } & 13.5 & 13.50 & 13.50 \\
\hline 4 & \multicolumn{2}{|c|}{ Baca nilai skala pasir Pemeriksaan (3) - Pemeriksaan (1) } & 3.50 & 3.50 & 3.50 \\
\hline \multirow{2}{*}{5} & \multirow{2}{*}{ Nilai Sand Equivalent } & Skala Pasir (4) X $100 \%$ & \multirow{2}{*}{64.81} & \multirow{2}{*}{63.64} & \multirow{2}{*}{66.04} \\
\hline & & Skala Lumpur (2) & & & \\
\hline 6 & \multicolumn{2}{|c|}{ Rata - rata nilai Sand Equivalent } & \multicolumn{3}{|c|}{64.83} \\
\hline
\end{tabular}


Perencanaan proporsi campuran menggunakan metode dari spesifikasi Depkimpraswil 2002. Dari perhitungan yang dilakukan kita dapat menentukan perkiraan kadar aspal awal. Dari proporsi yang telah ditentukan, Perhitungan kadar aspal tengah yang diperoleh mendekati nilai 7,5\%, yang kemudian diurutkan dua variasi kadar aspal ke bawah dan dua variasi kadar aspal ke atas dengan interval 0,5\%. Dari hasil perhitungan perkiraan kadar aspal diperoleh lima variasi kadar aspal yaitu $6 \%, 6,5 \%, 7 \%, 7,5 \%$ dan $8 \%$. Persentase terhadap berat total agregat yang digunakan yaitu 1200 gram.

Tabel 3. Proporsi Agregat dalam Campuran

\begin{tabular}{|c|c|c|c|}
\hline No & Jenis Besar Butiran Agregat & $\begin{array}{c}\text { Persentase } \\
\text { Terhadap Total } \\
\text { Agregat }\end{array}$ & $\begin{array}{c}\text { Kadar Aspal } \\
(\%)\end{array}$ \\
\hline 1 & Ban Dalam Bekas & $100 \%$ & $6 \%, 6,5 \%, 7 \%$, \\
& & $1,5 \%, 8 \%$
\end{tabular}

Sumber: Hasil Perhitungan (2021)

Berdasarkan proporsi yang telah ditetapkan, selanjutnya dilakukan perhitungan berat material dan aspal untuk pembuatan benda uji.

Tabel 4. Rencana Komposisi Campuran

\begin{tabular}{|c|c|c|c|c|c|c|c|c|c|c|c|c|c|}
\hline \multirow{4}{*}{ Komposisi } & \multicolumn{6}{|c|}{ Berat Total Agregat 1200 gram } & Berat & \multicolumn{5}{|c|}{ Variasi Kadar Aspal } & \multirow{4}{*}{$\begin{array}{c}\text { Kode } \\
\text { Sampel }\end{array}$} \\
\hline & \multirow{2}{*}{\multicolumn{2}{|c|}{$\begin{array}{c}\text { Agregat } \\
\text { Kasar }\end{array}$}} & \multirow{2}{*}{\multicolumn{2}{|c|}{ Abu Batu }} & \multirow{2}{*}{\multicolumn{2}{|c|}{ Pasir }} & Total & $6 \%$ & $6,5 \%$ & $7 \%$ & $7,5 \%$ & $8 \%$ & \\
\hline & & & & & & & Campuran & \multicolumn{5}{|c|}{ Berat Kadar Aspal Terhadap Total Campuran } & \\
\hline & $\%$ & gram & $\%$ & gram & $\%$ & gram & gram & \multicolumn{5}{|c|}{ Gram } & \\
\hline I & 36 & 432 & 36 & 408 & 28 & 360 & 1200 & 76,596 & 83,422 & 90,323 & 97,297 & 104,348 & A \\
\hline
\end{tabular}

Sumber: Hasil Perhitungan (2021)

Dari hasil perhitungan berat jenis dan penyerapan terhadap total agregat untuk campuran $A C-B C$ diperoleh hasil sebagai berikut. 
Tabel 5. Perhitungan Berat Jenis dan Penyerapan terhadap Total Agregat

\begin{tabular}{|c|c|c|c|}
\hline \multirow[b]{2}{*}{ Pemeriksaan } & \multicolumn{3}{|c|}{ Eks. Hampangen } \\
\hline & Agregat Kasar & Abu Batu & Pasir \\
\hline Berat Jenis $\left(\mathrm{gram} / \mathrm{cm}^{3}\right)$ & 2.707 & 2.689 & 2.552 \\
\hline $\begin{array}{l}\text { Berat Jenis Kering } \\
\left.\text { Permukaan/SSD (gram/ } / \mathrm{cm}^{3}\right)\end{array}$ & 2.726 & 2.710 & 2.599 \\
\hline Berat Jenis Semu $\left(\mathrm{gram} / \mathrm{cm}^{3}\right)$ & 2.760 & 2.745 & 2.679 \\
\hline Penyerapan (\%) & 0.710 & 0.754 & 1.849 \\
\hline Keausan/Abrasi (\%) & 14,12 & - & - \\
\hline
\end{tabular}

Sumber: Hasil Pemeriksaan (2021)

Tabel 6. Hasil Pengujian Marshall untuk Komposisi

\begin{tabular}{|c|c|c|c|c|c|c|}
\hline \multirow{2}{*}{$\begin{array}{c}\text { Kadar } \\
\text { Aspal (\%) }\end{array}$} & $\begin{array}{c}\text { Stabilitas } \\
(\mathrm{kg})\end{array}$ & $\begin{array}{c}\text { VMA } \\
(\%)\end{array}$ & $\begin{array}{c}\text { VIM } \\
(\%)\end{array}$ & $\begin{array}{c}\text { VFB } \\
(\%)\end{array}$ & $\begin{array}{c}\text { MQ } \\
(\mathrm{kN} / \mathrm{mm})\end{array}$ & \multirow{2}{*}{ Keterangan } \\
\hline 6 & 1274,480 & 20,69 & 6,33 & 69,40 & 455,546 & VIM Tidak Memenuhi \\
\hline 6,5 & 1345,426 & 20,94 & 5,25 & 74,94 & 433,724 & VIM Tidak Memenuhi \\
\hline 7 & 1407,026 & 21,52 & 4,56 & 78,84 & 435,174 & VIM Tidak Memenuhi \\
\hline 7,5 & 1274,480 & 22,58 & 4,43 & 80,37 & 420,215 & VIM Tidak Memenuhi \\
\hline 8 & 1243,892 & 22,21 & 2,53 & 88,62 & 416,073 & Memenuhi \\
\hline Spesifikasi & $>600$ & $>14$ & $2-4$ & $>65$ & $>250$ & \\
\hline
\end{tabular}

Sumber: Hasil Pengujian Marshall (2021) 


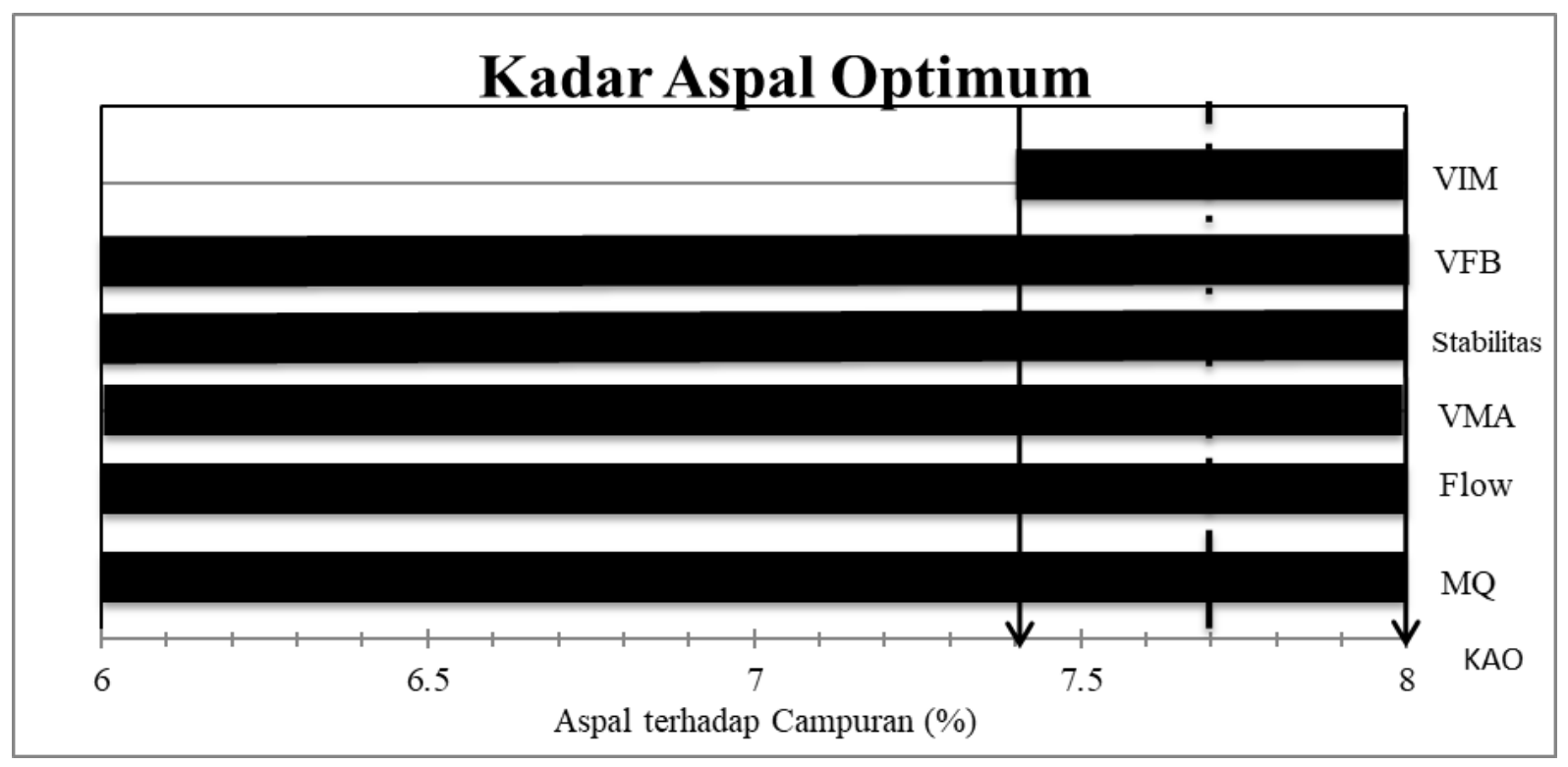

Gambar 1. Grafik Hubungan Parameter Marshall yang memenuhi Spesifikasi terhadap Variasi Kadar Aspal

Tabel 7. Nilai Parameter Marshall pada Kadar Aspal Optimum

\begin{tabular}{|c|c|c|c|c|c|c|c|}
\hline & & \multicolumn{5}{|c|}{ Parameter Marshall } \\
\cline { 4 - 8 } $\begin{array}{c}\text { Komposisi } \\
\text { Campuran }\end{array}$ & $\begin{array}{c}\text { Asal } \\
\text { Material }\end{array}$ & $\begin{array}{c}\text { KAO } \\
(\%)\end{array}$ & $\begin{array}{c}\text { Stabilitas } \\
(\mathrm{kg})\end{array}$ & $\begin{array}{c}\text { Flow } \\
(\mathrm{mm})\end{array}$ & $\begin{array}{c}\text { Rongga } \\
\text { dalam } \\
\text { Campuran } \\
(\mathrm{VIM})(\%)\end{array}$ & $\begin{array}{c}\text { Rongga } \\
\text { Terisi } \\
\text { Aspal } \\
(\mathrm{VFB})(\%)\end{array}$ & $\begin{array}{c}\text { Hasil } \\
\text { Bagi } \\
\text { Marshall } \\
(\mathrm{kg} / \mathrm{mm})\end{array}$ \\
\hline pasir alami & $\begin{array}{c}\text { Desa } \\
\text { Taringen }\end{array}$ & 7,850 & 330 & 2,9 & 4,8 & 77,00 & 115,5 \\
\hline Spesifikasi & & & $\begin{array}{c}\text { Min. } \\
200\end{array}$ & $2-3$ & $3-6$ & Min. 75 & Min. 80 \\
\hline
\end{tabular}

Sumber: Hasil Pengujian Marshall (2021)

\section{PENUTUP}

\section{Kesimpulan}

Berdasarkan hasil penelitian dan pembahasan yang telah diuraikan sebelumnya, pada "Analisis Karakteristik Marshall Campuran Asphalt ConcreteBinder Course (AC-BC) menggunakan Bahan Tambah "Ban Dalam Bekas Kendaraan Roda Empat" ini disimpulkan beberapa hal sebagai berikut:

1. Agregat Penyusun dalam perencanaan campuran Asphalt Concrete-Binder Course $(A C-B C)$ dari hasil pemeriksaan sifat-sifat fisik agregat berupa pemeriksaan gradasi (analisa saringan), berat jenis dan penyerapan, dan keausan agregat kasar semuanya memenuhi persyaratan spesifikasi. 
JURNAL KACAPURI

JURNAL KEILMUAN TEKNIK SIPIL

Volume 4 Nomor 2 Edisi Desember 2021

2. Komposisi yang dihasilkan dalam perencanaan campuran Asphalt ConcreteBinder Course $(A C-B C)$ terdiri dari 36\% agregat kasar, 36\% abu batu dan 28\% Pasir.

3. Hasil penelitian terhadap Parameter Marshall dengan variasi kadar aspal 6,5\%, 7,0\%, 7,5\%, 8,0\% dan 8,5\% diperoleh Kadar Aspal Optimum (KAO) senilai $7,70 \%$.

4. Hasil penelitian terhadap parameter karakteristik Marshall menggunakan komposisi campuran yang sama dan Kadar Aspal Optimum (KAO) senilai 7,70\% dengan bahan tambah Ban Dalam Bekas Kendaraan Roda Empat, variasi kadar bahan tambah sebesar 2\%, 4\%, 6\%, 8\% dan 10\% dari berat aspal yang diperoleh dari Kadar Aspal Optimum (KAO), dihasilkan nilai karakteristik parameter Marshall sebagai berikut:

Nilai stabilitas untuk semua variasi kadar bahan tambah ban dalam memenuhi spesifikasi yang disyaratkan. Nilai stabilitas tertinggi terdapat pada penambahan kadar ban dalam $10 \%$ yaitu sebesar 1458,01 kg. Nilai Stabilitas yang dihasilkan meningkat seiring dengan penambahan persentase kadar ban dalam.

a. Nilai Nilai Rongga antar butiran agregat (VMA) untuk semua variasi kadar bahan tambah ban dalam bekas memenuhi spesifikasi yang disyaratkan. Rongga antar butiran agregat (VMA) tertinggi terdapat pada penambahan kadar ban dalam $10 \%$ yaitu sebesar $23,81 \%$.

b. Nilai rongga udara dalam campuran (VIM) untuk variasi kadar bahan tambah ban dalam bekas persentase $2 \%, 4 \%, 6 \%$, dan $8 \%$, tidak memenuhi spesifikasi dan untuk variasi kadar bahan Nilai rongga dalam campuran (VIM) untuk persentase bahan ban dalam bekas tambah $10 \%$ yaitu sebesar $3,96 \%$, memenuhi spesifikasi nilai yang disyaratkan dari Spesifikasi. Nilai VIM tertinggi yang memenuhi spesifikasi pada kadar penambahan ban dalam $2 \%$, yaitu sebesar $6,23 \%$. Nilai rongga dalam campuran (VIM) yang dihasilkan cenderung menurun dengan penambahan persentase kadar bahan tambah ban dalam bekas.

c. Nilai rongga terisi aspal (VFB) untuk semua variasi kadar bahan tambah ban dalam memenuhi spesifikasi yang disyaratkan. Nilai VFB terbesar yaitu pada penambahan kadar ban dalam bekas persentase $10 \%$ yaitu besarnya $81,99 \%$. Nilai rongga terisi aspal (VFB) cenderung meningkat seiring dengan besarnya persentase kadar penambahan ban dalam bekas yang ditambahkan ke campuran. Hal tersebut disebabkan karena ban dalam bekas ikut bercampur dengan aspal dan juga mengisi rongga-rongga yang ada pada campuran.

d. Nilai hasil bagi Marshall (Marshall Quotient) untuk semua variasi kadar bahan tambah ban dalam memenuhi spesifikasi yang disyaratkan. Nilai hasil bagi Marshall (Marshall Quotient) tertinggi terdapat pada penambahan kadar Ban Dalam Bekas 4,0\% yaitu sebesar 435,477 kg/mm dan nilai terendah terdapat pada penambahan kadar ban dalam $10 \%$ yaitu sebesar 421,738 $\mathrm{kg} / \mathrm{mm}$.

5. Berdasarkan hasil penelitian terhadap parameter karakteristik Marshall dengan variasi kadar bahan tambah ban dalam bekas yang sudah dilakukan, dibuat grafik 
hubungan antara parameter Marshall campuran aspal dengan persentase kadar bahan tambah yang digunakan untuk menentukan nilai kadar ban dalam optimum. Didapatkan kadar penambahan ban dalam bekas optimum sebesar 7,70\%. Nilai parameter karakteristik Marshall pada Kadar Aspal Optimum (KAO) dan penambahan ban dalam bekas pada kadar ban dalam bekas optimum menghasilkan stabilitas sebesar 1458,01 kg, VMA sebesar 23,81\%, rongga dalam campuran (VIM) sebesar 3,96\%, rongga terisi aspal (VFB) sebesar 81,99\% dan hasil bagi Marshall (MQ) sebesar 421, $738 \mathrm{~kg} / \mathrm{mm}$.

Penambahan ban dalam bekas kendaraan roda empat sebesar 7,70\% dari berat aspal, dapat mempengaruhi parameter karakteristik Marshall nilai stabilitas naik 11,53\% dari nilai stabilitas campuran tanpa menggunakan bahan tambah yaitu mengalami kenaikan sebesar $150 \mathrm{~kg}$, nilai VMA naik sebesar $0,75 \%$, rongga dalam campuran (VIM) turun sebesar 0,75\%, rongga terisi aspal (VFB) naik sebesar 4,90\% dan hasil bagi Marshall (Marshall Quotient) naik sebesar 30,6 kg/mm.

\section{DAFTAR PUSTAKA}

Sugiyanto, G, 2008, Kajian Karakteristik Campuran Hot Rolled Asphalt Akibat Penambahan Limbah Parutan Karet Bekas,

ASTM (American Society for Testing and Material).

Asphalt Institute, 1985, A Basic Asphalt Emulsion Manual, USA.

Salim, A., 2010, Pengunaan Agregat Alam Pulau Simeulue dan Semen Portland Sebagai Filler untuk Lapis Permukaan Jalan, Bidang Studi Teknik Transportasi Fakultas Teknik Universitas Syiah Kuala, Banda Aceh.

PBI, 1971, Peraturan Beton Indonesia 1971 (PBI 71), Dirjend Cipta Karya DPU 1971.

Kardiyono, T, 1996, Teknologi Beton, Biro Penerbit Keluarga Mahasiswa Teknik Sipil Universitas Gadjah Mada, Yogyakarta.

Direktorat Jenderal Bina Marga, 2010, Revisi 3 (2014), Seksi 6.3 Spesifikasi Campuran Beraspal Panas, Direktorat Jenderal Bina Marga, Departemen PU, Jakarta.

Sukirman, S, 2003, Campuran Beraspal Panas, Penerbit Granit, Bandung.

Faisal, 2013, Karakteristik Marshall Campuran Aspal Beton AC-BC Menggunakan Material Agregat Basalt dan Aspal Pen. 60/70 dengan Tambahan Parutan Ban Dalam Bekas Kendaraan Kendaraan Roda 4, Jurnal Teknik Sipil, Universitas Syiah Kuala,Vol.3, No. 3, Agustus 2014.

Departemen Pekerjaan Umu, 2018, Spesifikasi Umum 2018 Revisi 2, Jakarta. 